granulocyte macrophage colony stimulating factor. ${ }^{17-19}$ The explanation for the occurrence of caseous necrosis is not clear and we did not find any other aetiological agent that could be responsible for it. Caseous necrosis may have resulted from an imbalance in the immune system of this patient, who presented with a bone marrow aplasia with leucopenia.

The presence of focal caseous necrosis in late stage acute leishmaniasis, in which parasites are scanty or absent, ${ }^{18}$ can lead to difficulties in diagnosis. Tuberculosis, ${ }^{20}$ presenting as the lupus vulgaris or the subcutaneous gumma form with spread into the upper dermis, is the main differential diagnosis. Syphilis at the late secondary stage should also be considered, as well as acne agminata and sarcoidosis with fibrinoid necrosis. ${ }^{20}$ In addition, patients may not have generated antibodies directed against either amastigote or promastigote antigens. ${ }^{3}$ As cutaneous leishmaniasis is being encountered more often because of international travel and the influx of immigrants from areas of the world where this parasite is endemic, expedient diagnosis of this condition may be hampered by the presence of caseous necrosis in skin biopsy specimens.

1 Farah FS, Malak JA. Cutaneous leishmaniasis. Arch Dermatol 1971;103:467-74.

2 Strick RA, Borok M, Gasiorowski HC. Recurrent cutaneous leishmaniasis. F Am Acad Dermatol 1983;9:437-43.

3 Stratigos JD. New aspects on cutaneous leishmaniasis. Derm Beruf Unwelt 1980;28:139-48.

4 Berlin C. Leishmania recidiva cutis. Arch Dermatol Syph 1940;41:874-85.
5 Dostrowsky A. Relapses in cutaneous leishmaniasis. Ann Trop Med 1936;30:267-74.

6 Biagi F. Sintesis de historias clinicas de leishmaniasis tegumentaria de Mexico (ulcera de los chicleros). Medicina Mexico 1953;33:385-96.

7 Al-GindanY, Abdul-Aziz O, Kubba R. Cutaneous leishmaniasis in Al-Hassa, Saudi Arabia. Int $\mathcal{f}$ Dermatol 1984; 23:194-7.

8 Kurban AK, Malak JA, Farah FS, Chaglassian HT. Histopathology of cutaneous leishmaniasis. Arch Dermatol 1966;93:396-401.

9 Ridley DS. The pathogenesis of cutaneous leishmaniasis. Trans $R$ Soc Trop Med Hyg 1979;73:150-60.

10 Ridley DS, Ridley MJ. Late-stage cutaneous leishmaniasis: immunopathology of tuberculoid lesions in skin and lymph nodes. Br f Exp Pathol 1984;65:337-46.

11 Rioux JA, Lanotte G, Serres E, Pratlong F, Bastien P, Perriere J. Taxonomy of Leishmania. Use of isoenzymes. Suggestions for a new classification. Ann Parasitol Hum Comp 1990;65:111-25.

12 Paksoy N, Hekim E. Comparative analysis of clinicopathological features in cutaneous leishmaniasis and lupus vulgaris in Turkey. Trop Med Parasitol 1993;44:37-9.

13 Convit J, Kerdel-Vegas F. Disseminated cutaneous leishmaniasis. Arch Dermatol 1965;91:439-47.

14 Sangueza OP, Sangueza JM, Stiller MJ, Sangueza P. Mucocutaneous leishmaniasis: a clinicopathologic classification. f Am Acad Dermatol 1993;28:927-32.

15 Essa MH, Mangoud AM, Morsy TA, Aly MA, Salama MM Vascular changes in cutaneous leishmaniasis. $\mathcal{f}$ Egypt Soc Parasitol 1989;19:683-7.

16 Ridley MJ, Ridley DS. Cutaneous leishmaniasis: immune complex formation and necrosis in the acute phase. $\mathrm{Br} \mathcal{F}$ Exp Pathol 1984;65:327-36.

17 Locksley RM, Heinzel FP, Sadick MD, Holaday BJ, Gardner KD Jr. Murine cutaneous leishmaniasis susceptibility correlates with differential expansion of helper T-cell subsets. Ann Inst Pasteur 1987;138:744-9.

18 Pirmez C, Cooper C, Paes Oliveira M, Schubach A, Torigian VK, Modlin RL. Immunologic responsiveness in American cutaneous leishmaniasis lesions. $\mathcal{F}$ Immunol 1990;145:3100-4

19 Esterre P, Dedet JP, Frenay C, Chevallie M, Grimaud JA. Cell populations in the lesion of human cutaneous leishmaniasis: a light microscopical, immunohistochemicaland ultrastructural study. Virchows Arch A Pathol Anat Histopathol 1992;421:239-47.

$20 \mathrm{McKee}$ PH, Marsden PA. In: Pathology of the skin: with clinical correlations. New York: JB Lippincott, 1989:819-20.

\title{
Carcinosarcoma arising in a dermoid cyst of the ovary
}

\author{
D S Arora, S Haldane
}

Department of

Histopathology,

Royal Devon and

Exeter Healthcare

NHS Trust,

Exeter

D S Arora

$S$ Haldane

Correspondence to:

Dr D S Arora,

Department of

St James's University

Hospital,

Beckett Street,

Leeds LS9 7TF

Accepted for publication 16 January 1996

\begin{abstract}
A case of carcinosarcoma arising within an otherwise benign cystic teratoma is reported. The patient, a 78 year old nulliparous woman, presented with right sided abdominal pain of short duration and subsequently underwent a bilateral salphingo-oophorectomy. Slicing of the left ovary revealed a unilocular cyst containing hair admixed with soft yellow material with a thin wall apart from a solid area at one pole. Extensive areas of necrosis and cystic degeneration were present within this mass. Histologically, the large cyst was a typical mature cystic teratoma, containing carcinomatous and sarcomatous elements. Mature cystic teratomas have been reported in association with a variety of malignant ovarian tumours such as mucinous cystadenocarci-
\end{abstract}

noma and malignant germ cell neoplasms. Secondary malignant transformation within a dermoid cyst is a much rarer occurrence, estimated as less than $2 \%$ of all such lesions. Adenocarcinomas are the second most common malignancies arising within dermoid cysts. Sarcomas alone or in combination with squamous carcinoma have been described arising in a mature cystic teratoma. To the best of our knowledge, no case of sarcoma arising in association with adenocarcinoma has been described before.

( Clin Pathol 1996;49:519-521)

Keywords: ovary, dermoid cyst, carcinosarcoma.

Malignant transformation within a mature cystic teratoma (dermoid cyst) occurs in less than 
$2 \%$ of cases ${ }^{1}$ and most commonly results in a squamous cell carcinoma (75-85\%). Other reported malignancies include adenocarcinoma $(7 \%)$, various pure sarcomas $(7 \%)$, melanomas and basal cell carcinomas (each less than $1 \%$ ), and anaplastic carcinoma. Here, we describe a case of carcinosarcoma arising within an otherwise benign cystic teratoma which, to our knowledge, is the first reported case of such a combination.

\section{Case report}

A 78 year old nulliparous women presented with right sided abdominal pain of short duration. On examination, a large mobile mass was present in the lower abdomen. Ultrasound showed a partly solid and partly cystic ovarian mass. The patient underwent a bilateral salphingo-oophorectomy two days after admission.

\section{Pathological findings}

The left ovary was enlarged and measured $23 \times$ $17 \times 15 \mathrm{~cm}$. Slicing revealed a unilocular cyst, $14 \mathrm{~cm}$ in diameter, containing hair admixed with soft yellow material with a thin wall apart from a solid area at one pole, measuring $10 \times 8$ $\times 7 \mathrm{~cm}$. Extensive areas of necrosis and cystic degeneration were present within this mass. The right ovary and both fallopian tubes appeared normal.

Histologically, the large cyst was a typical mature cystic teratoma lined by squamous epithelium and adnexal structures (fig 1 inset). The solid component consisted of glandular structures set in an abundant cellular stroma. Glands showed both secreted and intracellular periodic acid Schiff positive diastase resistant mucin, and varied in architecture from rounded acinar structures to poorly differentiated signet ring cells (fig 1A). The stroma consisted of uniform plump mesenchymal cells with high nuclear cytoplasmic ratios (fig 1B). Some smooth muscle differentiation was present, but no differentiation towards any other mesenchymal elements was identified. The carcinomatous and sarcomatous elements were closely associated and intermixed with each other. Mitoses were abundant in both the glandular and stromal components, including some abnormal forms. There were extensive areas of necrosis. No benign glandular epithelium was present.

\section{Immunohistochemical findings}

The glandular component stained positively for carcinoembryonic antigen (Dako, Glostrup, Denmark) and CAM 5.2 (Becton Dickinson, California, USA). The malignant stromal component was positive for vimentin and showed mild positivity for $\alpha$ smooth muscle actin (Sigma, Poole, Dorset, UK), and equivocal staining for desmin (Dako). Neither component stained positively for S-100 (Dako), neuron specific enolase (Dako), chromogranin (Dako), or synatophysin (Dako).

\section{Discussion}

Mature cystic teratomas have been reported in association with a variety of malignant ovarian
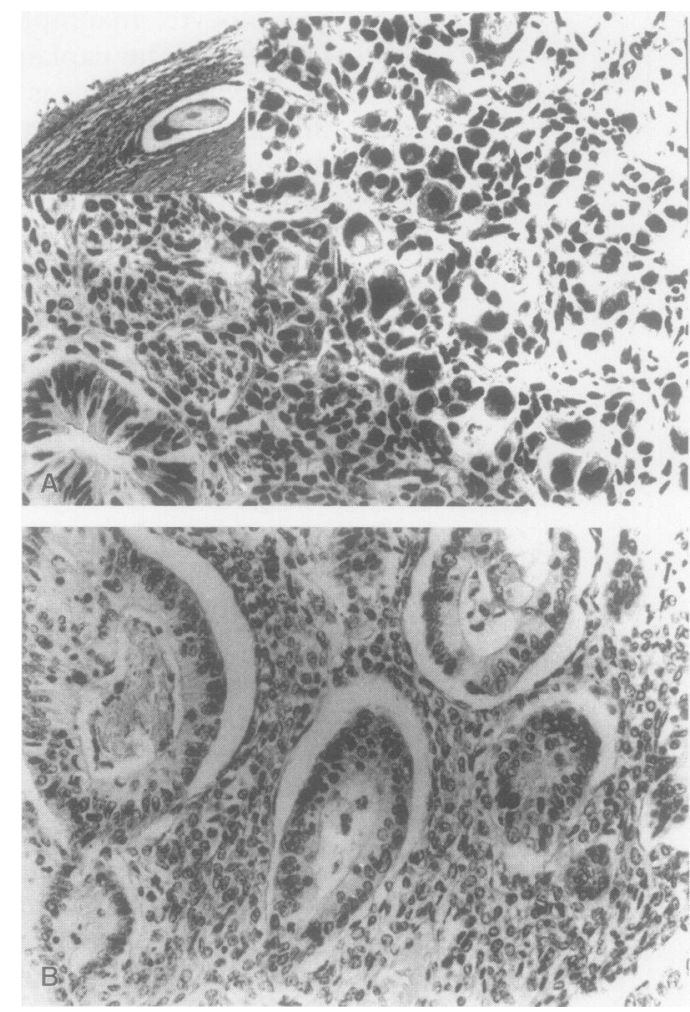

Figure 1 Inset, dermoid cyst; $A$, malignant glandular component, some of which shows signet ring forms; $B$, sarcomatous component.

Table 1 Secondary maligant transformation within a dermoid cyst

Squamous cell carcinoma ${ }^{1}$

Adenocarcinoma ${ }^{1}$

Malignant melanoma

Non-Hodgkin's lymphoma

Sebaceous carcinoma

Apocrine carcinoma ${ }^{2}$

Adenosquamous carcinoma ${ }^{1}$

Small cell carcinoma ${ }^{3}$

Clear cell carcinoma

Undifferentiated carcinoma ${ }^{1}$

Basal cell carcinoma

Extramammary Paget's disease

Fibrosarcoma

Leiomyosarcoma

Osteogenic sarcoma

Chondrosarcoma

Malignant fibrous histiocytoma

Squamous cell carcinoma and sarcoma ${ }^{5} 6$

tumours such as mucinous cystadenocarcinoma and malignant germ cell neoplasms. ${ }^{1}$ Secondary malignant transformation within a dermoid cyst is a much rarer occurrence, estimated as less than $2 \%$ of all such lesions. ${ }^{1}$ Table 1 shows the variety of reported tumour types in this situation.

We are confident that our case presented with primary ovarian disease, as there was no evidence of any other primary site and the tumour was confined to the left ovary. The striking production of neutral mucins, glandular architecture and foci of signet ring morphology suggest expression of an upper gastrointestinal phenotype, although no corresponding benign glandular epithelium was identified. The stroma consisted of uniform plump cells with a high nuclear:cytoplasmic ratio and with focal expression of smooth muscle antigens but no differentiation towards other mesenchymal phenotypes. 
Our case must be distinguished from malignant mixed müllerian tumour which occurs in the same age group and has carcinomatous and sarcomatous components. However, these tumours are generally solid, lack the characteristic squamous epithelial lined cyst and show different mucin expression. Immature malignant teratoma occurs in a younger age group and shows a variety of lines of mesenchymal differentiation, notably towards neural elements, which were absent in this case.

Germ cell tumours of all types derive from neoplastic totipotent stem cells whose progeny retain the ability to differentiate towards tissues of all three embryonic somatic layers and the transitional extraembryonal structures. The original pattern of the better differentiated members of this group suggests that local cellular influences are important in determining the final phenotype expressed by individual cells. The histological behaviour and histological appearances of these tumours are determined by the degree to which this embryogenetic environmental responsiveness is retained. In contrast, our case resembles carcinosarcomas at other sites in that there was an essentially random mixture of stromal and epithelial elements. This reflects a probabilistic commitment of individual cells and clones to one or other expressed phenotype without regard to organogenetic influences. Our case implies glandular malignant transformation within the previously benign, fully differentiated, glandular component of a mature cystic teratoma, although no premalignant changes were identified despite thorough sampling.

Adenocarcinomas are the second most common malignancies arising within dermoid cysts $^{1}$ and may display gastrointestinal phenotypes, but lack the malignant stroma as in our case. Sarcomas alone or in combination with squamous carcinoma ${ }^{56}$ have been described arising in a mature cystic teratoma. To the best of our knowledge, no case of sarcoma arising in association with adenocarcinoma has been described before.

The prognosis of patients with malignant transformation in teratoma is very poor, with most women dying within one year. ${ }^{1}$ Occasional cases with prolonged survival have been reported. $^{7}$ Poor prognostic factors include tumour dissemination, cyst wall invasion, ascites, spontaneous or accidental rupture, adhesions, and tumour type other than squamous carcinoma. Treatment is surgical, with pelvic clearance in most cases. Chemotherapy may be indicated according to the tumour type.

1 Russell P, Bannatyne P. Surgical pathology of the ovaries. Edinburgh: Churchill Livingstone, 1989:436-40.

2 Chang DH, Sueh S, Soong YK. Small cell carcinoma with neurosecretory granules arising in an ovarian dermoid cyst. Gynecol Oncol 1992;46:246-50.

3 Morimitsu Y, Nakashima O, Nakashima Y, Kojiro M, Shimokobe T. Apocrine adenocarcinoma arising in cystic teratoma of the ovary. Arch Pathol Lab Med 1993; 117:647-9.

4 Randall BJ, Ritchie C, Hutchison RS. Paget's disease and invasive undifferentiated carcinoma occurring in a mature cystic teratoma of the ovary. Histopathology 1991;18:469-

5 Genadry R, Parmley T, Woodruff JD. Secondary malignancies in benign cystic teratomas. Gynecol Oncol 1979;8:24651.

6 Hanada M, Tsujimura T, Shimizu H. Multiple malignancies (squamous cell carcinoma and sarcoma) arising in a
dermoid cyst of the ovary. Acta Pathol fpn 1981;31:681-8.

7 Ueda G, Fugita M, Ogawa H, Sawada $M$, Inoue $M$ Tanizawa $O$. Adenocarcinoma in a benign cystic teratoma of the ovary: report of a case with a long survival period. Gynecol Oncol 1993;48:259-63.

\title{
Tenascin in human papillomavirus associated lesions of the uterine cervix
}

Department of

Pathology,

University of Oulu,

Oulu, Finland

R Pöllänen

Y Soini

V-P Lehto

Department of

Obstetrics and

Gynaecology

$S$ Vuopala

Department of Public Health Sciences and General Practice

E Läärä

Correspondence to: DrY Soini,

Department of Pathology,

University of Oulu,

Kajaanintie $52 \mathrm{D}$,

FIN-90220 Oulu,

Finland.

Accepted for publication 4 December 1995

\author{
R Pöllänen, Y Soini, S Vuopala, E Läärä, V-P Lehto
}

Abstract

The immunohistochemical expression of tenascin was studied in 80 morphologically diagnosed condylomas and cervical intraepithelial neoplasia (CIN) lesions. The results were compared with the human papillomavirus (HPV) DNA subtype, which was determined by HPV dot blot and in situ hybridisation. Tenascin mRNA synthesis was also determined in 10 selected cases by in situ hybridisation. No statistically significant association was found between tenascin expression and the degree of dysplasia or the HPV subtype. There was, however, a strong cor- relation between the extent of tenascin immunoreactivity and the degree of inflammation. Synthesis of tenascin mRNA was detected in basal keratinocytes and in fibroblasts by in situ hybridisation. The lack of association between the grade of CIN and tenascin expression precludes its use as a marker of premalignancy in CIN. (f Clin Pathol 1996;49:521-523)

Keywords: tenascin, extracellular matrix proteins, human papillomavirus infection, HPV DNA, inflammation.

Human papillomavirus (HPV) is the aetiological agent of various genital lesions and there is 